\title{
"YO ESTUDIO, TÚ ESTUDIAS": O ENSINO DO ESPANHOL PARA FINS ESPECÍFICOS EM CURSOS DE SECRETARIADO NO BRASIL - PANORAMA E DESAFIOS EM INSTITUIÇÕES PÚBLICAS
}

\author{
Eduardo Cesar Pereira Souza ${ }^{1}$ \\ Emili Barcelos Martins Santos ${ }^{2}$
}

RESUMO: Este artigo tem por objetivo investigar sobre o ensino do Espanhol para Fins Específicos em Cursos de Secretariado de Instituições de Ensino Superior (IES) públicas brasileiras, evidenciando-se o atual panorama e seus desafios. No que diz respeito aos aspectos metodológicos, a pesquisa pode ser entendida como qualitativa (na abordagem do problema), exploratória (quanto aos objetivos) e documental (quanto aos procedimentos técnicos adotados). A partir dos resultados coletados foi possível perceber que o panorama encontrado corresponde à oferta da Língua Espanhola em dezesseis das vinte e uma IES pesquisadas e que os desafios percebidos estão no plano da aplicabilidade da disciplina no contexto do Secretariado, fato esse constatado após a consulta das ementas, dos conteúdos programáticos e das referências.

PALAVRAS-CHAVE: Ensino, Espanhol para Fins Específicos, Secretariado.

ABSTRACT: This article aims to investigate the teaching of Spanish for Specific Purposes in Brazilian public Secretarial Science courses, showing the current panorama and its

\footnotetext{
${ }^{1}$ Mestrando em Linguística na Universidade Cruzeiro do Sul (Unicsul), Bacharel em Secretariado Executivo pela Universidade Federal do Amapá (UNIFAP) e membro do Grupo de Pesquisas Interdisciplinares em Secretariado (GPISEC/UFS). E-mail: assessoria@ sinsesp.com.br

${ }^{2}$ Doutora e Mestre em Letras pela Universidade de São Paulo (USP). É graduada em Secretariado Executivo Trilíngue pela Universidade Federal de Viçosa (UFV). É presidente e sócia fundadora da Associação Brasileira de Pesquisa em Secretariado (ABPSEC). E-mail: emilimartins@yahoo.com.br
} 
challenges. As regards the methodological aspects, this article can be understood as qualitative (in addressing the problem), exploratory (on its targets) and documentary (concerning technical procedures adopted). From the collected data it was possible to observe that the overview found is the offering of the Spanish language in 16 of the 21 courses surveyed and that the perceived challenges are in terms of applicability of the discipline in the context of the secretarial field, a fact that was observed after the consultation of the course descriptions, contents and references.

KEYWORDS: Teaching, Spanish for Specific Purposes, Secretarial Science.

Recebido em 23/12/2016

Aceito em 23/02/2017

\section{INTRODUÇÃO}

Desde pequenas as pessoas são submetidas a algum processo de ensino/aprendizagem: aprendem a ler, aprendem a escrever, aprendem a usa a internet. Assim, de modo preliminar, pode-se conceituar o termo aprender como a capacidade de fazer algo que antes não fazíamos (LAKOMY, 2008). Não obstante, parece que a noção de aprendizagem é um tanto obscura, pois ela "envolve a interação de diversos fatores e processos através dos quais compreendemos conceitos de temas específicos, como matemática, português, desenho etc." (LAKOMY, 2008, p. 16).

Se a datar da fase infantil os indivíduos estão aprendendo, logo, pode-se inferir que o processo de aprendizagem é cíclico. Perpassa toda a vida, propositalmente ou não. Como diriam os mais ousados: "ninguém nasce sabendo". De fato, os seres humanos não nascem sabendo. Nesse percurso, o sujeito "toma para si nova forma de conduta, transforma a informação em conhecimento, hábitos e atitudes novas." (LAKOMY, 2008, p. 16). 


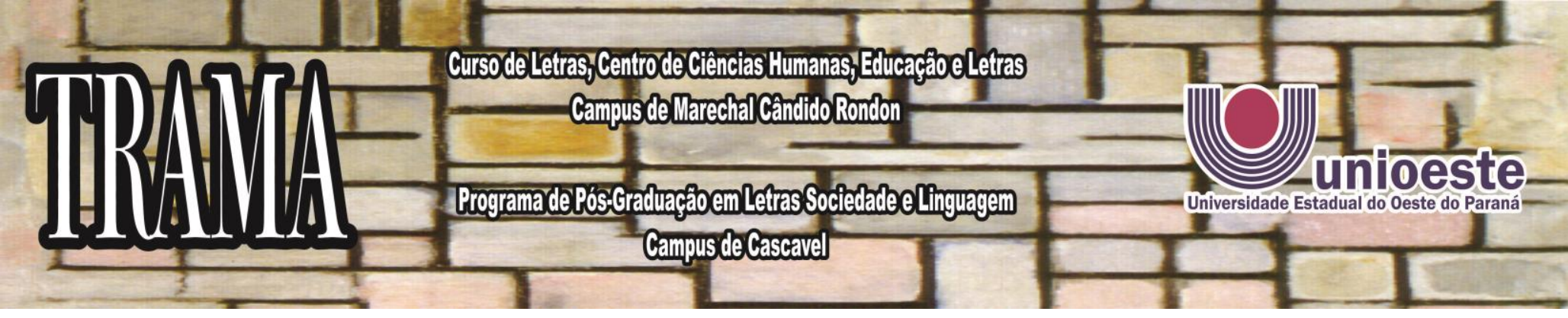

Um dos lugares no qual as pessoas comumente ensinam e aprendem é nas instituições de ensino. Por lá, se capacitarão naquilo que julgarem pertinente às suas formações. Dentre os objetivos dos aprendizes pode-se destacar a aprendizagem de novos idiomas, inclusive, para fins profissionais.

Considerando tais afirmativas, o lugar da Língua Espanhola no mundo e a necessidade de ensiná-la em diferentes países, parece importante destacar, que, no processo de ensinar e aprender línguas, alguns desafios percorrem o universo teórico-metodológico de docentes. Assim, pensa-se que os mais recorrentes estejam relacionados ao direcionamento de uma metodologia para o ensino de Língua Comum (LC) ou de Língua para Fins Específicos (LFE), neste caso, a dos Negócios, da Enfermagem, do Secretariado, da Medicina, do Direito etc.

Além disso, de acordo com Flores (2012), um dos pontos de notoriedade e frequentemente "destacado por especialistas que analisam a língua espanhola como recurso ou ativo econômico tem sido a globalização, vista como um dos fatores responsáveis pela valorização do espanhol como língua de comunicação internacional" (FLORES, 2012, p. 27-28). Logo, não se pode negar que esse idioma tem se consolidado como uma das línguas de negócios, além de ser considerado quando da comunicação internacional, a exemplo do que acontece na ONU (Organização das Nações Unidas) ${ }^{3}$.

Para Jesús Cosín (2007), as chamadas Línguas para Fins Específicos (doravante LFE) são espécies funcionais da língua comum. Em sentido amplo, "línguas de especialidades não estão separadas da língua geral, contanto que compartam com ela algumas particularidades de caráter estrutural, tais como fonologia, morfologia e sintaxe ${ }^{4 \text { ” }}($ COSÍ́N, 2007, p. 33). De modo preciso, “[...]

\footnotetext{
${ }^{3}$ Quando a ONU foi fundada, em 24 de outubro de 1945, ficou definido, na Carta da ONU que para seu melhor funcionamento seus membros, vindos de todos os cantos do planeta se comunicariam em seis idiomas oficiais: inglês, francês, espanhol, árabe, chinês e russo. Disponível em: https://nacoesunidas.org/conheca/

${ }^{4}$ No original, tradução nossa.
} 
num curso de línguas para fins específicos, o que se pretende é potencializar no aluno o desenvolvimento de uma competência limitada para que seja capaz de movimentar-se em contextos bem determinados" (RODRÍGUEZ, 2004, p. 7). Sendo assim, entende-se que a função das disciplinas de Espanhol para Secretariado é fomentar no futuro profissional o desenvolvimento de habilidades capazes de ajudá-lo no dia a dia de assessoria, junto aos gestores empresarias.

Tomando por base as argumentações apresentadas, constata-se que pontos teóricos diferentes são defendidos e que não há uma resposta final sobre qual caminho a escolher. Ademais, considerando a complexidade da língua, compete aos pesquisadores promover reflexões e estimular a elaboração de problemáticas que busquem respostas aos mais diferentes tipos de lacunas de pesquisa.

Neste sentido, surge o interesse em se pesquisar sobre o ensino do Espanhol para Fins Específicos em cursos de Secretariado de Instituições de Ensino Superior (IES) públicas brasileiras. De modo amplo, procura-se responder a seguinte questão-problema: Qual o atual panorama do ensino do Espanhol para Fins Específicos em cursos de Secretariado de Instituições de Ensino Superior (IES) públicas brasileiras? Como não temos a resposta para essa pergunta, procuraremos viabilizá-la a partir dos seguintes objetivos específicos: a) conhecer quais IES públicas brasileiras oferecem os cursos de Secretariado; b) conhecer quais IES oferecem disciplinas de Língua Espanhola; c) identificar em quais Instituições de Ensino essas disciplinas são direcionadas ao ensino específico, ou seja, aplicado ao Secretariado; e, d) identificar possíveis lacunas e propor saídas para superar tais desafios.

Lenguas de especialidad no están separadas de la lengua general, sino que comparten con ella algunos rasgos de carácter estructural, tales como la fonología, morfología y la sintaxis (COSÍN, 2007, p. 33).

${ }^{5}$ No original, tradução nossa.

[...] en un curso de lenguas con fines específicos, lo que se pretende es potenciar en el alumno el desarrollo de una competencia restringida para que sea capaz de manejarse en contextos muy determinados (RODRÍGUEZ, 2004, p. 7). 


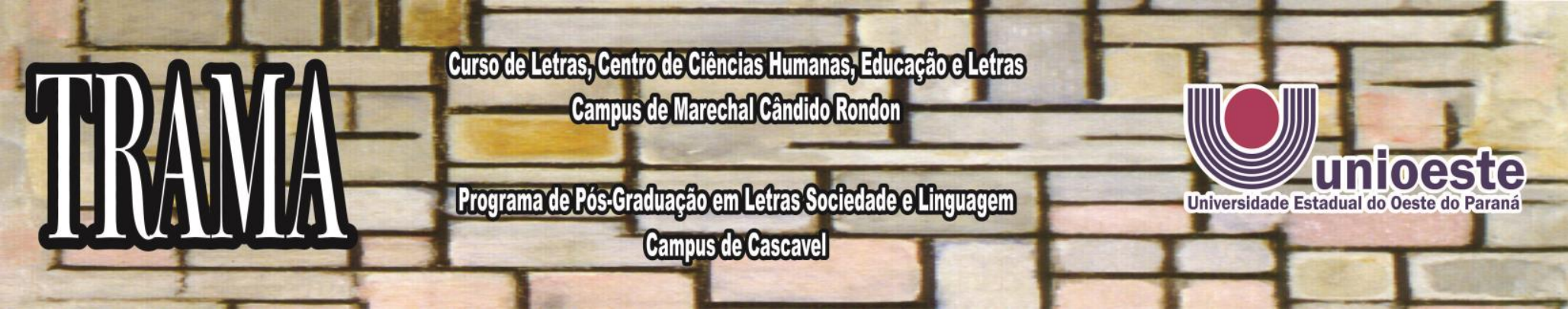

Este artigo está estruturado da seguinte forma: na Introdução, há a contextualização da pesquisa e suas variáveis de investigação. Posteriormente, tem-se o Referencial Teórico, no qual se procura explorar os trabalhos de estudiosos das áreas de Linguística e Secretariado. Em seguida, apresentamos a Metodologia empregada na realização deste trabalho, que se insere na perspectiva da pesquisa qualitativa, exploratória e documental. A próxima seção consiste na apresentação dos Resultados coletados e a Discussão desses dados. Por fim, tecem-se as Considerações Finais do estudo, do mesmo modo que se elencam as Referências utilizadas no trabalho.

\section{LÍNGUA ESPANHOLA: ESTUDAR POR QUE E PARA QUÊ?}

Ora, se este trabalho refere-se a uma língua mundial, conforme explicitou Sedycias (2005), estudá-la, certamente, possibilitará o vislumbre de novos horizontes em diversos planos: social, educacional, político ou profissional.

Em se tratando do Brasil, tem-se que estamos num continente com vários países cujas línguas oficiais são o espanhol: Argentina, Bolívia, Colômbia, Costa Rica, Cuba, Chile, El Salvador, Equador, Guatemala, Honduras, México, Nicarágua, Panamá, Paraguai, Peru, Porto Rico, República Dominicana, Uruguai e Venezuela. Assim sendo, percebe-se que há certa necessidade de ensinar e aprender tal idioma. Aos brasileiros, para que possam desfrutar das oportunidades de trabalho em diferentes nações, aprender o Espanhol pode representar um grande diferencial.

Embora não seja percebida por um grande número de pessoas, essa língua está muito presente no dia a dia dos povos das Terras Brasilis. Afinal de contas, depois da consolidação do Mercado Comum do Sul (MERCOSUL), da entrada 
desenfreada das multinacionais espanholas (Telefônica/Vivo, Banco Santander, Iberdrola, Gás Natural Fenosa, PricewaterhouseCoopers, Prosegur, KPMG, Iberia, dentre outras) e da "oferta obrigatória" de Espanhol no Ensino Médio (Lei n. 11.161, de 5 de agosto $2005^{6}$ ), tornou-se possível conviver, em algum momento, com essa língua estrangeira. Todavia, também devemos considerar que em diversos espaços da sociedade brasileira não há esse intercâmbio, inclusive para uma parcela importante da sociedade, aprender Espanhol é totalmente dispensável, pois a consideram muito próxima da Língua Portuguesa, ou seja, fácil. (FANJUL; GONZALEZ, 2014).

Se considerarmos o plano educacional temos um dos grandes propagadores do Espanhol no mundo, o Instituto Cervantes, entidade criada na Espanha em 1991, que tem por missão "promover, ensinar espanhol e divulgar a cultura da Espanha e dos países hispanofalantes" nos quatro cantos do mundo. Por aqui, há oito Centros de Ensino (São Paulo, Rio de Janeiro, Brasília, Curitiba, Porto Alegre, Salvador, Recife e Belo Horizonte), "sendo o país com maior número de Institutos em todo o mundo.” (INSTITUTO CERVANTES, 2017).

No entanto, não se pode deixar de destacar as representações que surgem quando se fala do ensino/aprendizagem da Língua Espanhola em contexto brasileiro. Conforme apontado por Almeida Filho (1995) a inicial facilidade percebida por aprendizes de línguas semelhantes (Português/Espanhol) pode se mostrar uma facilidade ilusória, uma vez que dá a impressão de que o estudante já domina o idioma. Paralelamente,

Essa proximidade revela outras questões, como a representação dos falantes de ambas as línguas de que o estudo de uma e de outra não seja necessário, lançando-se mão da

\footnotetext{
${ }^{6}$ Revogado pela Lei n. 13.415, de 2017.
} 
de textos profissionais especializados, inclusive em idioma estrangeiro; [...]VII Versão e tradução em idioma estrangeiro, para atender as necessidades de comunicação da empresa" (BRASIL, 1985). Evidentemente, em quantos mais ele obtiver proficiência, melhor preparado para os desafios do mercado de trabalho estará. Dentre as línguas estrangeiras de maior pungência no mundo dos negócios podemos destacar o Inglês, o Espanhol, o Francês, o Italiano, o Alemão, o Mandarim e o Japonês.

Cabe destacarmos, ainda, que as habilidades linguísticas e comunicativas, desde os remotos tempos dos Escribas, são exigidas para o desempenho das tarefas do dia a dia dos secretários. Acerca disso, Sabino e Rocha (2004) escreveram: “[...] sócios da nobreza tiveram secretários que exerciam tarefas bastante semelhantes as que são exigidas para a profissão, na atualidade [...]. A maioria dominava vários idiomas, inclusive latim; [...]" (SABINO; ROCHA, 2004, p. 7, grifo nosso).

Não obstante, Sanctis e Abib (2010) evidenciaram que o profissional de secretariado passou a ter um papel que vai além de assessor. Assim, esse novo perfil exige uma maior atenção do secretário no que diz respeito ao uso da língua estrangeira em negociações contratuais e reuniões entre diferentes empresas.

Somando-se a isso, nota-se que o contato com outras línguas, neste contexto globalizado, não se dá apenas pessoalmente, mas, também, por diversas alternativas trazidas pela tecnologia: e-mails, telefonemas, cartas, videoconferências, dentre outras (ABDALLA, 2009; SOUZA, 2015).

A seguir, dissertamos sobre o paradoxo existente entre o ensino de Língua Geral versus de Fins Específicos. 


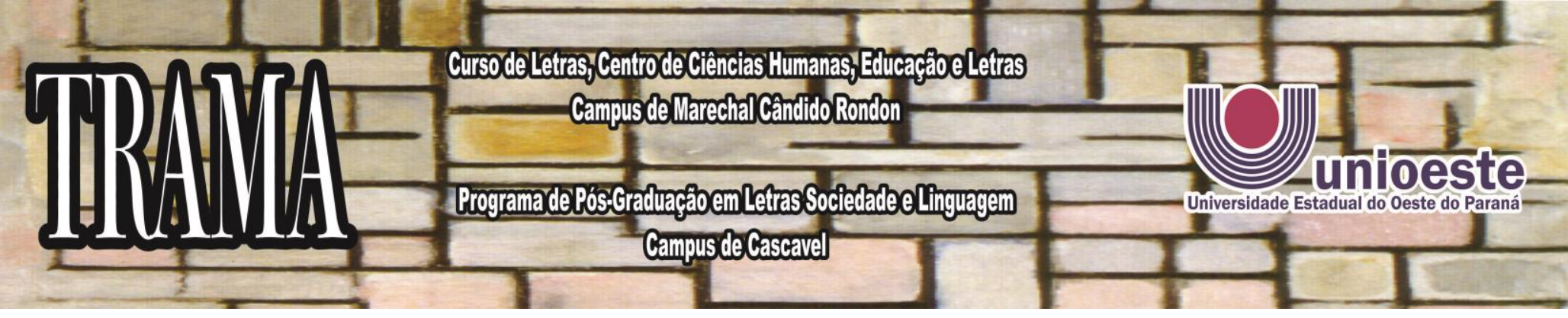

\section{O ENSINO DO ESPANHOL PARA FINS ESPECÍFICOS: ENSINAR} PARA ADVOGADOS, MÉDICOS OU SECRETÁRIOS?

Os debates acerca da Língua Geral (usual, universal) versus Língua para Fins Específicos suscitam diferentes perspectivas teóricas. Assim, parece pertinente revisitar os escritos de Babo (1999, p. 240) quando diz que a diferença entre essas duas terminologias reside na "predominância de determinados aspectos, quanto a formas e funcionamentos de uma dada língua e o abandono ou adiamento de outros. Estamos em presença da segmentação institucional de uma língua [...]." Em outras palavras, "o que diferencia um curso para fins específicos de um curso para fins gerais são os seus objetivos." (GUIMARÃES, 2014, p. 1). No primeiro há a predominância de necessidades e interesses bem delimitados, que são trabalhados pelos docentes que modo pontual, no segundo, essas prerrogativas se mostram mais difusas, ou seja, não é objetivo do professor trabalhar somente com as questões referentes a um determinado contexto.

Para este estudo, resolveu-se por adotar o Ensino para Fins Específicos, pois se acredita que no contexto secretarial ele seja o mais adequado, uma vez que no espaço do trabalho serão exigidas competências não exploradas no Ensino Geral: atendimento telefônico, redação de e-mails, cartas, memorandos, organização de eventos, traduções técnicas etc.

Celani (1981) esclarece que num curso com objetivos específicos "os fins para os quais o aluno necessita de uma determinada língua podem ser mais facilmente percebidos e definidos" (CELANI, 1981, p. 5). Dessa forma, já que se trata da formação de secretários, entendemos que o aprendizado de um léxico 
específico ao mundo dos negócios será requerido, em detrimento de informações genéricas sobre o idioma.

Sanctis e Abib (2010) ressaltaram, também, que para a escolha de metodologia voltada ao ensino regular (língua comum) ou de fins específicos (especialidades), é pertinente que os docentes verifiquem os pontos fortes e vulneráveis dos alunos, do mesmo modo que suas habilidades e experiências de aprendizagem adquiridas ao longo do tempo, afim de que possam inferir as lacunas no arcabouço das ideias do alunado.

Ao estudar materiais didáticos de Espanhol para Secretariado, Souza (2015) constatou que existem lacunas nas produções investigadas e sugeriu que fossem incorporados nas produções futuras a abordagem das seguintes temáticas: tópicos especiais em discurso empresarial, tópicos de tradução em contextos empresariais, cultura empresarial em países hispânicos, expressões idiomáticas de diferentes países hispânicos, técnicas de elaboração de documentos organizacionais (atas, ofícios, requerimentos, declarações, memorandos, dentre outros).

Como foi possível perceber, as problemáticas de cunho metodológico (escolha do caminho mais apropriado para se seguir no ensino de LE) não é parte inerente apenas às outras áreas. Elas também fazem parte do cotidiano secretarial, que se reinventa no espaço escolar e organizacional.

\section{METODOLOGIA}

A metodologia possui um papel de relevância na pesquisa, pois apresenta os passos com que ela foi desenvolvida. Não obstante, almeja oferecer ao leitor informações para a compreensão e entendimento do estudo em questão. 
De acordo com Bruyne; Herman e Schoutheete (1991)

[...] a metodologia deve ajudar a explicar não apenas os produtos da investigação científica, mas principalmente seu próprio processo, pois suas exigências não são de submissão estrita a procedimentos rígidos, mas antes da fecundidade na produção dos resultados (BRUYNE; HERMAN E SCHOUTHEETE, 1991, p. 29).

Assim, no que diz respeito à abordagem do problema tem-se que se trata de um trabalho, predominantemente, qualitativo, já que de acordo com Minayo (2001), essa abordagem "trabalha com o universo de significados, motivos, aspirações, crenças, valores e atitudes, o que corresponde a um espaço mais profundo das relações, dos processos e dos fenômenos que não podem ser reduzidos à operacionalização de variáveis”. (MINAYO, 2001, p. 14).

Quanto aos objetivos e aos fins, a pesquisa se caracteriza como exploratória, uma vez que na perspectiva de Selltiz et al (1965) os estudos exploratórios são todos aqueles que buscam descobrir ideias e intuições, na tentativa de adquirir maior familiaridade com o fenômeno pesquisado.

Em relação aos meios, a pesquisa é documental, pois de acordo com Lakatos e Marconi (2001) a coleta de dados é realizada em fontes primárias, como documentos escritos ou não, pertencentes a arquivos públicos; arquivos particulares de instituições e domicílios, e fontes estatísticas.

A priori, procurou-se mapear as IES públicas de todo o país, entre estaduais e federais, que ofertam o Curso de Secretariado (bacharelado e tecnólogo). O resultado encontrado pode ser visualizado no Quadro 1, a seguir:

Quadro 1 - Relação de IES públicas ofertantes do Curso de Secretariado

\begin{tabular}{|c|c|c|}
\hline Região & Estado & IES \\
\hline \multirow{3}{*}{ Norte } & Amapá & 1. Universidade Federal do Amapá - UNIFAP (B) \\
\hline & Pará & 2. Universidade do Estado do Pará - UEPA (B) \\
\hline & Roraima & 3. Universidade Federal de Roraima - UFRR (B) \\
\hline
\end{tabular}




\begin{tabular}{|c|c|c|}
\hline \multirow{6}{*}{ Nordeste } & Bahia & 4. Universidade Federal da Bahia - UFBA (B) \\
\hline & Ceará & 5. Universidade Federal do Ceará - UFC (B) \\
\hline & Paraíba & 6. Universidade Federal da Paraíba - UFPB (B) \\
\hline & Pernambuco & 7. Universidade Federal de Pernambuco - UFPE (B) \\
\hline & Piauí & $\begin{array}{l}\text { 8. Instituto Federal de Educação Ciência e Tecnologia } \\
\text { do Piauí - IFPI (T) }\end{array}$ \\
\hline & Sergipe & 9. Universidade Federal de Sergipe - UFS (B) \\
\hline \multirow{2}{*}{$\begin{array}{l}\text { Centro- } \\
\text { Oeste }\end{array}$} & $\begin{array}{l}\text { Mato } \\
\text { Grosso }\end{array}$ & $\begin{array}{l}\text { 10. Instituto Federal de Educação Ciência e Tecnologia } \\
\text { de Mato Grosso - IFMT (B) }\end{array}$ \\
\hline & DF & $\begin{array}{l}\text { 11. Instituto Federal de Educação Ciência e Tecnologia } \\
\text { de Brasília - IFB (T) }\end{array}$ \\
\hline \multirow{3}{*}{ Sudeste } & $\begin{array}{l}\text { Minas } \\
\text { Gerais }\end{array}$ & 12. Universidade Federal de Viçosa - UFV (B) \\
\hline & \multirow[b]{2}{*}{ São Paulo } & 13. Faculdade de Tecnologia de São Paulo (T) \\
\hline & & $\begin{array}{l}\text { 14. Faculdade de Tecnologia de Carapicuíba, } \\
\text { Itaquaquecetuba e São Caetano do Sul* }(\mathrm{T})\end{array}$ \\
\hline \multirow{7}{*}{ Sul } & \multirow{6}{*}{ Paraná } & 15. Universidade Estadual de Londrina - UEL (B) \\
\hline & & 16. Universidade Estadual de Maringá - UEM (B) \\
\hline & & 17. Universidade Federal do Paraná - UFPR (T) \\
\hline & & $\begin{array}{l}\text { 18. Universidade Estadual do Centro Oeste - Unicentro } \\
\text { (B) }\end{array}$ \\
\hline & & 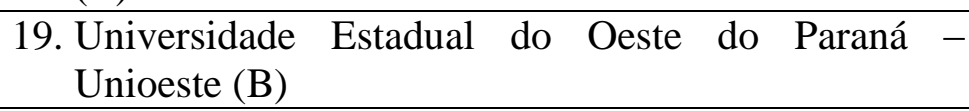 \\
\hline & & 20. Universidade Estadual do Paraná - Unespar (B) \\
\hline & $\begin{array}{c}\text { Santa } \\
\text { Catarina }\end{array}$ & 21. Universidade Federal de Santa Catarina - UFSC (B) \\
\hline
\end{tabular}

*A mesma matriz curricular é adotada para essas três unidades da Fatec.

Legenda: B - Bacharelado; T - Tecnólogo.

Fonte: Sítio das universidades.

A escolha de apenas IES públicas se justifica no pressuposto de que, atualmente, nos dados do sistema e-MEC, página administrada pelo Ministério da Educação, existem mais de 100 (cem) Instituições cadastradas, entre as quais, muitas já não ofertam o Curso de Secretariado, e dentre aquelas que ainda o fazem, há algumas que possuem as plataformas sem informações sobre o curso, consequentemente, inviabilizando/dificultando o andamento deste trabalho.

Após apresentarmos a listagem das IES públicas ofertantes dos cursos de Secretariado no Brasil, de acordo com quadro anterior, convém destacar que 
algumas delas não disponibilizam disciplinas de Espanhol como Língua Estrangeira (ELE), como é o caso da UNIFAP e UFSC e, em outras, a LE é optativa, neste caso, UFC, UFPE e UEM.

Diante disso, a relação de IES que oferecem as disciplinas de LE, na modalidade obrigatória, é apresentada no Quadro 2 que se segue:

Quadro 2 - Relação de IES que oferecem disciplinas de ELE na modalidade obrigatória

\begin{tabular}{|c|c|c|}
\hline Região & Estado & IES \\
\hline \multirow{2}{*}{ Norte } & Pará & $\begin{array}{l}\text { 1. UEPA (Espanhol I, Espanhol II, Espanhol III e } \\
\text { Espanhol IV). }\end{array}$ \\
\hline & Roraima & $\begin{array}{l}\text { 2. UFRR (Língua Espanhola I, Língua Espanhola II, } \\
\text { Língua Espanhola III e Redação Empresarial em } \\
\text { Língua Espanhola). }\end{array}$ \\
\hline \multirow{4}{*}{ Nordeste } & Bahia & $\begin{array}{l}\text { 3. UFBA (Espanhol I, Espanhol II, Espanhol III e } \\
\text { Espanhol IV). }\end{array}$ \\
\hline & Paraíba & $\begin{array}{l}\text { 4. UFPB (Língua Espanhola I, Língua Espanhola II, } \\
\text { Língua Espanhola III, Língua Espanhola IV, Língua } \\
\text { Espanhola V, Redação Comercial em Espanhol e } \\
\text { Técnicas de Tradução em Espanhol). }\end{array}$ \\
\hline & Piauí & 5. IFPI (Espanhol aplicado I e Espanhol aplicado II). \\
\hline & Sergipe & $\begin{array}{l}\text { 6. UFS (Espanhol para fins específicos I e Espanhol para } \\
\text { fins específicos II). }\end{array}$ \\
\hline \multirow{2}{*}{$\begin{array}{l}\text { Centro- } \\
\text { Oeste }\end{array}$} & $\begin{array}{c}\text { Mato } \\
\text { Grosso }\end{array}$ & $\begin{array}{l}\text { 7. IFMT (Língua Espanhola I, Língua Espanhola II e } \\
\text { Língua Espanhola III). }\end{array}$ \\
\hline & $\overline{\mathrm{DF}}$ & $\begin{array}{l}\text { 8. IFB (Espanhol aplicado ao Secretariado I, Espanhol } \\
\text { aplicado ao Secretariado II e Espanhol aplicado ao } \\
\text { Secretariado III). }\end{array}$ \\
\hline \multirow[t]{5}{*}{ Sudeste } & $\begin{array}{l}\text { Minas } \\
\text { Gerais }\end{array}$ & $\begin{array}{l}\text { 9. UFV (Língua Espanhola I, Língua Espanhola II, } \\
\text { Língua Espanhola III e Espanhol Empresarial). }\end{array}$ \\
\hline & São Paulo & $\begin{array}{l}\text { 10. Fatec SP (Espanhol I, Espanhol II, Espanhol III, } \\
\text { Espanhol IV e Espanhol V). }\end{array}$ \\
\hline & São Paulo & $\begin{array}{l}\text { 11. Fatec de Carapicuíba, Itaquaquecetuba e São Caetano } \\
\text { do Sul (Espanhol I, Espanhol II, Espanhol III, } \\
\text { Espanhol IV e Espanhol V, Espanhol VI, Espanhol VII } \\
\text { e Espanhol VIII)*. }\end{array}$ \\
\hline & & $\begin{array}{l}\text { 12. UEL (Língua Espanhola I, Língua Espanhola II e } \\
\text { Língua Espanhola III). }\end{array}$ \\
\hline & & 13. Unicentro (Espanhol aplicado ao Secretariado I, \\
\hline
\end{tabular}


próximo objetivo deste estudo. Para tanto, adentrou-se às matrizes curriculares dos cursos.

Antes de apresentar o Quadro 3 é importante destacar que, para saber se a disciplina estava voltada ao ensino específico ou não, além de averiguar junto a ementa, conteúdos programáticos e referências, procurou-se descobrir se eram exploradas questões do ambiente secretarial, tais como: elaboração/revisão de currículo, técnicas de entrevista de emprego, redação empresarial/oficial, cultura empresarial nos países hispânicos, técnicas de tradução em contextos empresariais, tratamentos de cortesia em reunião de negócios, cerimonial e organização de eventos, preparação de reuniões, atendimento/realização de chamadas telefônicas, planejamento de viagens, vocabulário em contexto empresarial, recepção de visitantes, conversação em língua espanhola para negócios etc.

Dessa forma, o Quadro 3 ilustra as informações verificadas para essa proposição.

Quadro 3 - Relação de IES nas quais as disciplinas de LE são voltadas ao ensino para fins específicos

\begin{tabular}{|c|c|c|c|}
\hline Região & Estado & \multicolumn{1}{|c|}{ IES } \\
\hline Norte & Roraima & 1. UFRR (Redação Empresarial em Língua Espanhola). \\
\hline \multirow{2}{*}{ Nordeste } & Paraíba & 2. UFPB (Redação Comercial em Espanhol). \\
\cline { 2 - 4 } & Sergipe & $\begin{array}{l}\text { 3. UFS (Espanhol para fins específicos I e Espanhol para } \\
\text { fins específicos II). }\end{array}$ \\
\hline $\begin{array}{c}\text { Centro- } \\
\text { Oeste }\end{array}$ & DF & $\begin{array}{l}\text { 4. IFB (Espanhol aplicado ao Secretariado I, Espanhol } \\
\text { aplicado ao Secretariado II e Espanhol aplicado ao } \\
\text { Secretariado III). }\end{array}$ \\
\hline Sudeste & Minas & 5. UFV (Espanhol Empresarial). \\
\hline \multirow{2}{*}{ Sul } & Gerais & $\begin{array}{l}\text { 6. Unicentro (Espanhol aplicado ao Secretariado I, } \\
\text { Espanhol aplicado ao Secretariado II e Espanhol } \\
\text { aplicado ao Secretariado III). }\end{array}$ \\
\cline { 2 - 4 } & 7. UFPR (Língua Espanhola II, Língua Espanhola III, \\
\hline
\end{tabular}


produções textuais em Espanhol aplicadas ao secretariado - nível III: ofício, documentos de rotina em escritórios, contratos e atas de reuniões.

A UFPR, por sua vez, nas disciplinas de Língua Espanhola II, Língua Espanhola III, Língua Espanhola IV e Língua Espanhola V, procura explorar os conteúdos: desenvolvimento da competência comunicativa com ênfase em textos técnicos para uso institucional; domínio de léxico geral e específico em questões empresarias, para a elaboração de diversos tipos de correspondências comerciais em nível básico e intermediário; desenvolvimento de estratégias para planejar e executar comunicações internas e em diversas situações laborais e sociais; compreensão e interpretação de informações de gênero comercial tanto do âmbito oral como escrito.

Finalmente, na Unioeste, em Língua Espanhola I, Língua Espanhola II e Língua Espanhola III, a ementa estabelece o desenvolvimento das seguintes habilidades e competências: introdução no léxico voltado ao ambiente mercadológico, administrativo e organizacional; o Espanhol como instrumento de trabalho; incremento das destrezas de compreensão, leitura, redação e conversação; as técnicas de correspondência comercial e atividades que se baseiam na rotina da atividade de secretário/a; ampliação léxica referente ao vocabulário específico do ambiente organizacional e institucional, bem como o domínio da linguagem técnica, comercial e administrativa.

A seguir, realizam-se as considerações finais desta pesquisa com vistas a responder a questão-problema proposta no início deste trabalho: Qual o atual panorama do ensino do Espanhol para Fins Específicos em cursos de Secretariado de Instituições de Ensino Superior (IES) públicas brasileiras? 


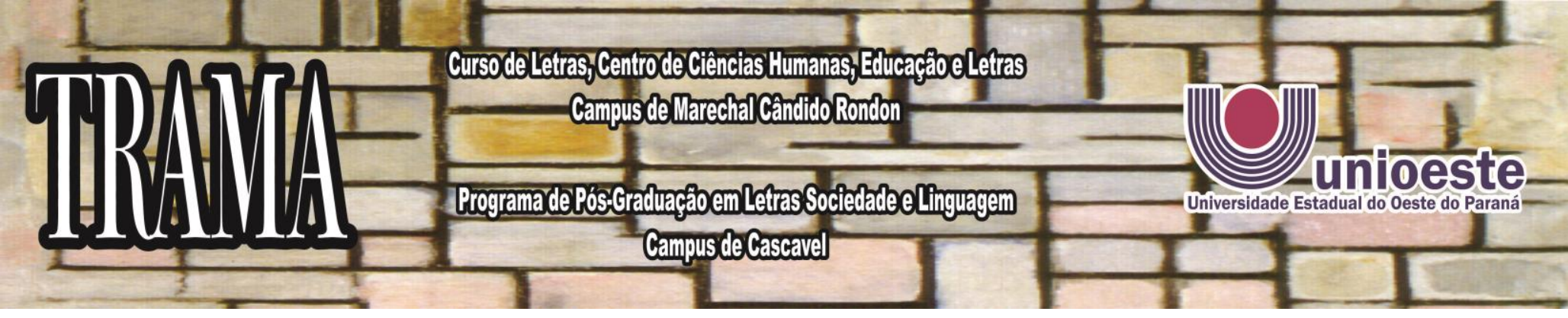

Por meio da análise das ementas, conteúdos programáticos e referências utilizadas nas IES públicas pesquisadas, ofertantes dos cursos de Secretariado, foi possível mapear aquelas que empregam a metodologia voltada para o ensino com fins específicos, num total de oito: UFRR, UFPB, UFS, IFB, UFV, Unicentro, UFPR e Unioeste.

Conforme destacado por Rodrigues (2004) “[...] num curso de línguas para fins específicos, o que se pretende é potencializar no aluno o desenvolvimento de uma competência limitada para que seja capaz de movimentar-se em contextos bem determinados" (RODRIGUES, 2004, p. 7). Dessa forma, percebe-se que as instituições de ensino destacadas no parágrafo anterior estão fazendo sua parte no sentido de formar secretários, com habilidades em Língua Espanhola, específicas para o mercado de trabalho secretarial.

As limitações encontradas para esta pesquisa estão no plano do não acesso às ementas, conteúdos programáticos e referências adotadas pelas instituições: UEPA, UFBA, IFMT, IFPI, Fatec SP, Fatec de Carapicuíba, Fatec de Itaquaquecetuba, Fatec de São Caetano do Sul, UEL e Unespar. A existência de sites genéricos e sem informações suficientes sobre os cursos comprometem o desenvolvimento das pesquisas na área de secretariado.

Este trabalho não teve a intenção de esgotar o tema pesquisado. Pelo contrário, será de grande valia, para o desenvolvimento das pesquisas secretariais, que outros estudiosos explorem temáticas semelhantes a essa ou que deem um novo olhar para esta que se finaliza. 


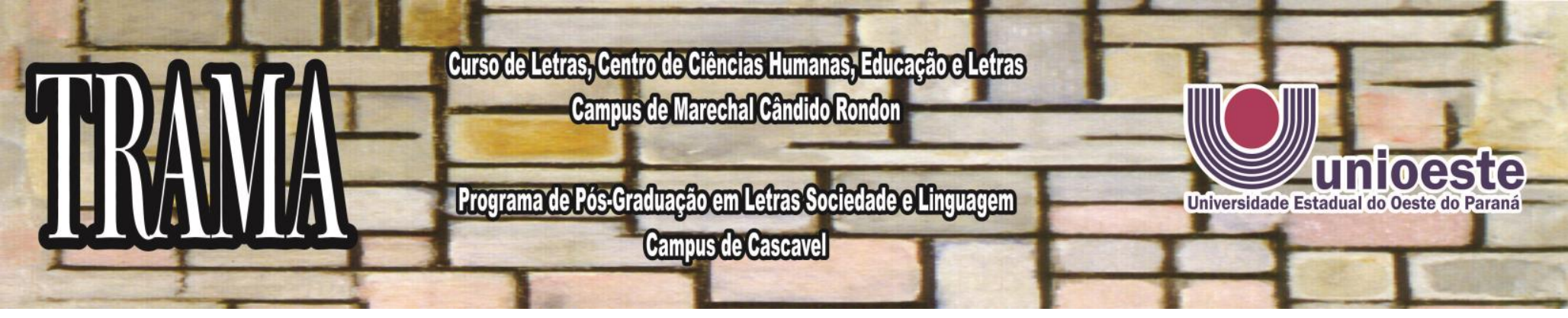

\section{REFERÊNCIAS}

ABDALLA, G. C. O Espanhol na Prática do Secretário hoje: mapeando os gêneros com base na análise de necessidades. In: V SIGET - Simpósio Internacional de Estudos De Gêneros Textuais. Anais... Caxias do Sul, Rio de Grande do Sul, 2009.

BABO, M. A. M. M. A língua estrangeira para fins específicos: uma língua mutilada? In: $4^{\circ}$ Encontro Nacional do Ensino das Línguas Vivas no Ensino Superior Em Portugal. Actas... Porto, Portugal, 1999. Disponível em: http://ler.letras.up.pt/uploads/ficheiros/6086.pdf Acesse em 25 fev. 2017.

BRASIL, Presidência da República. Casa Civil. Subchefia para assuntos jurídicos. Lei ${ }^{\circ} 7377$, de 30 de setembro de 1985. Dispõe sobre o exercício da profissão de Secretário e dá outras providências. Brasília. DF, 1985.

. Lei $n^{\circ} 9261$, de 10 de janeiro de 1996 . Altera a redação dos incisos I e II do art. $2^{\circ}, o$ caput do art. $3^{\circ}, o$ inciso VI do art. $4^{\circ}$ e o parágrafo único do art. $6^{\circ}$ da Lei $\mathbf{n}^{\mathbf{0}} \mathbf{7 . 3 7 7}$, de 30 de setembro de 1985. Brasília. DF, 1996.

BRASIL. MEC, CNE. Resolução $n^{\circ}$. 3, de 23 de Junho de 2005. Institui as diretrizes curriculares para os cursos de graduação em Secretariado Executivo e dá outras providências. Brasília. DF, 2005.

BRUYNe, P; HeRman, J; SCHOUTheete, M. Dinâmica da Pesquisa em Ciências Sociais: os pólos da prática metodológica. Rio de Janeiro: Livraria Francisco Alves, 1991.

CELANI, M. A. A. O ensino de inglês instrumental em universidades brasileiras. the ESPecialist, 3. São Paulo: PUC-SP, 1981.

COSÍN, J. M. La enseñanza/aprendizaje del español como lengua extranjera para fines académicos: área de Letras, Máster en Enseñanza de Español como Lengua Extranjera. Universidad de Alcalá, Alcalá de Henares, 2007.

FANJUL, A. P.; GONZALEZ, N. T. M. (Orgs.). Espanhol e português brasileiro: estudos comparados. 1a . ed. São Paulo: Parábola, 2014.

FERREIRA, A. I. A interlíngua do falante de espanhol e o papel do professor: aceitação tácita ou ajuda para superá-la? In: ALMEIDA FILHO, J. C. P, (org). 
Português para Estrangeiros: Interface com o Espanhol. Campinas: Pontes, 2001.

FLORES, R. C. S. O Espanhol em ambiente corporativo: reflexões sobre o ensino para fins específicos. 2012. Dissertação de Mestrado (Mestrado em Estudos da Linguagem) - Universidade Federal Fluminense, Niterói, 2012.

GUIMARÃES, R. M. O Ensino de Línguas para Fins Específicos (ELFE) no Brasil e no mundo: ontem e hoje. Revista História do Ensino de Línguas no Brasil, Ano 8, n. 8, 1/2014. Disponível em: http://www.helb.org.br/index.php/revista-helb/ano-8-no-8-12014/227-o-ensinode-linguas-para-fins-especificos-elfe-no-brasil-e-no-mundo-ontem-e-hoje Acesso em: 25 fev. 2017.

INSTITUTO CERVANTES. O Instituto Cervantes no Brasil. Instituto Cervantes. Disponível em: http://saopaulo.cervantes.es/br/quem_somos_brasil_espanhol.htm Acesso em: 25 de fev. 2017.

LAKATOS, E. M.; MARCONI, M. A. Fundamentos da metodologia científica. 4. ed. São Paulo: Atlas, 2001.

LAKOMY, A. M. Teorias cognitivas da aprendizagem. 2. ed. ver. e atual. Curitiba: Ibpex, 2008.

MINAYO, M. C. S. Ciência, técnica e arte: o desafio da Pesquisa Social. In: . (Org.) Pesquisa social: teoria, método e criatividade. Petrópolis: Vozes, 2001, p. 09-30.

RODRÍGUEZ, M. Fernández-Conde. La enseñanza de la comunicación no verbal en un curso del Español de los Negocios según la ELMT. Memoria de Máster. Universidad Antonio de Nebrija, Hanoi, 2004. Disponível em: http://www.mecd.gob.es/redele/Biblioteca-Virtual/2004/memoriaMaster/2-

Semestre/FERNANDEZ-CONDE.html Acesso em: 16 fev. 2015.

SABINO, R. F; ROCHA, F. G. Secretariado: do escriba ao web writer. Rio de Janeiro: Brasport, 2004. 
